\title{
IDENTIFICAÇÃO DE ÁREAS DE DESCARTE IRREGULAR DE RESÍDUOS NA ZONA LESTE DO MUNICÍPIO DE PRESIDENTE PRUDENTE - SP E ELABORAÇÃO DE MATRIZ DE IMPACTOS
}

João Vitor de S. Palmeira; Mariana Andrade; Nelissa Garcia Balarim

Universidade do Oeste Paulista - UNOESTE, Curso de Engenharia Ambiental, Presidente Prudente, SP., E-mail: nelissa@unoeste.br

\section{RESUMO}

A geração de resíduos em grande escala tornou-se uma constante preocupação das cidades, principalmente com relação à forma incorreta de descarte deste material, sendo assim o presente estudo teve como objetivo identificar e mapear as áreas de descarte irregular de resíduos sólidos na Zona Leste de Presidente Prudente e elaboração de Matriz de interação para análises de aspecto e impactos. Foram percorridos 36 bairros, nos quais notou-se que o descarte ocorria em áreas impróprias, como em Áreas de Preservação Permanente - APP.

Palavras-chave: Resíduos Sólidos Urbanos, Descarte Irregular, Matriz de Interação, Impactos ambientais, Políticas públicas.

\section{IDENTIFICATION OF IRREGULAR DISPOSAL OF WASTE IN THE EAST ZONE OF THE PRESIDENTE PRUDENTE - SP AND ELABORATION OF A MATRIX OF IMPACTS.}

\begin{abstract}
]
The generation of waste on a large scale has become a constant concern of the cities, especially in relation to the incorrect disposal of this material, thus the present study aimed to identify and map the irregular disposal areas of solid waste in the East Zone of Presidente Prudente, and elaboration of a Matrix to study the related impacts. There were covered 36 districts, where was observed that the disposal occurred in unsuitable areas, such as in Permanent Preservation Areas PPA.

Keywords: Urban Solid Waste; Irregular Disposal, Interaction Matrix, Impacts Evaluation, Public
\end{abstract} Politics. 


\section{INTRODUÇÃO}

Atualmente o descarte inadequado dos resíduos sólidos representa uma das maiores preocupações dos municípios brasileiros, devido à capacidade que eles têm de degradar o meio ambiente e prejudicar a saúde (ARAúJO; PIMENTEL, 2016).

É considerado descarte inadequado, qualquer lançamento indevido de resíduos, no chão, ruas, lagoas, praias, rios, praças, e em qualquer outro lugar passível de ilegalidade. Seja por negligência, falta de conhecimento ou até pela certeza de impunidade de suas ações (TAVARES et al. 2008; SANTOS E FELIPE, 2015).

A disposição inadequada dos Resíduos Sólidos Urbanos (RSU) é oriunda de diversos fatores, como, crescimento populacional, a ausência de conscientização ambiental, carência de infraestrutura e de políticas públicas que visem à melhoria da gestão dos resíduos sólidos (SILVA; LIPORONE, 2011).

No município de Presidente Prudente - SP, mesmo com a coleta do lixo atendendo toda área urbana, é comum ver o acúmulo inadequado de RSU's em diversos pontos periféricos da cidade, causando problemas de ordem ambiental, social, saúde pública, econômica e de estética paisagística.

Como impactos negativos associados ao descarte irregular dos resíduos, é possível citar: a proliferação de animais transmissores potenciais de doenças, poluição do ar, do solo e da água. Agravando ainda mais a situação, a água da chuva pode lixiviar os poluentes, poluindo as águas superficiais ou as águas subterrâneas devido à infiltração no solo (AZEVEDO, 2004).

Desta forma, é importante tomar conhecimento das causas e consequências do acúmulo dos RSU's, pois é através destes estudos que o poder público poderá tomar as providências cabíveis e propor novas políticas públicas que poderão ser implantadas a fim de atender ao correto gerenciamento dos resíduos sólidos.

O presente trabalho busca diagnosticar e identificar áreas de descarte irregular na Zona leste do município bem como elaborar uma matriz de interação para estudar os aspectos e impactos associados.

\section{METODOLOGIA}

Este estudo foi desenvolvido na Zona Leste do município de Presidente Prudente -SP, que ao longo da história apresentou-se como uma das áreas mais utilizadas para o descarte dos RSU's. A coleta de dados foi realizada por meio de visitas, a fim de identificar os pontos de descarte irregular, durante o mês de março de 2016, com o auxílio do mapa da área de estudo, câmera fotográfica e GPS. 


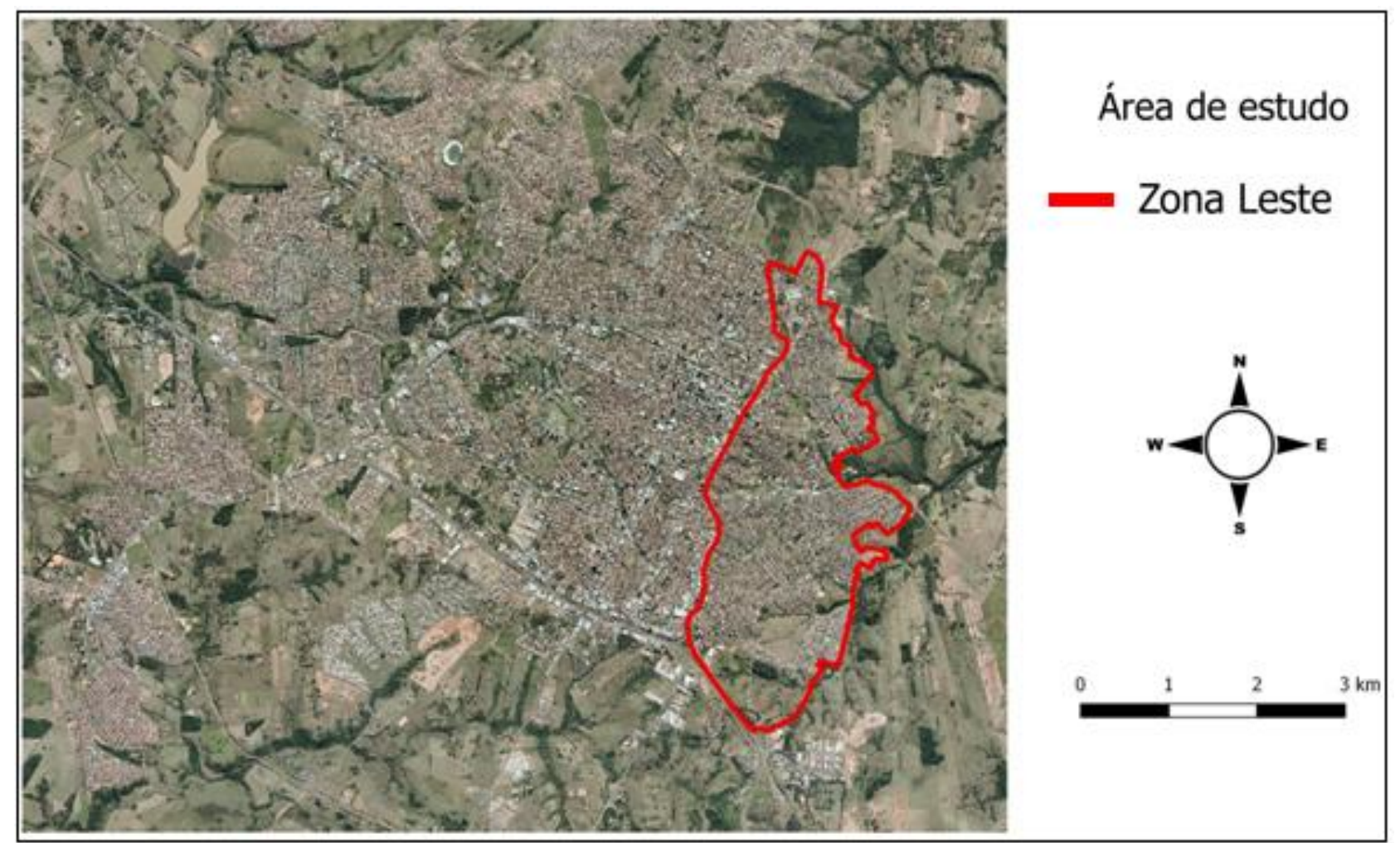

Figura 1. Mapa da localização da área de estudo.

Fonte: Os Autores, 2016.

Após a realização do levantamento in loco, foi elaborado o mapa com os pontos de descarte irregular com suas respectivas coordenadas geográficas, com auxílio software de geoprocessamento QuantumGis.

A fim de analisar os possíveis impactos ambientais decorrentes desta atividade foi elaborado a Matriz de Interação Aspecto/Impacto Ambiental. A aplicação do método da matriz de interação apresentar de forma simples e direta os aspectos ambientais e os impactos decorrentes dessa ação no meio ambiente (SÁNCHES, 2010).

\section{RESULTADOS}

Ao percorrer os 36 bairros foram identificados 145 pontos de descarte irregular de RSU's na Zola Leste do Município (Figura 2). Observou-se que a disposição irregular de RSU ocorre em áreas que apresentam fácil acesso da população como ao longo da Linha Férrea, ruas, avenidas marginais, nos fundos de vale e APP's sem cerca de proteção. 


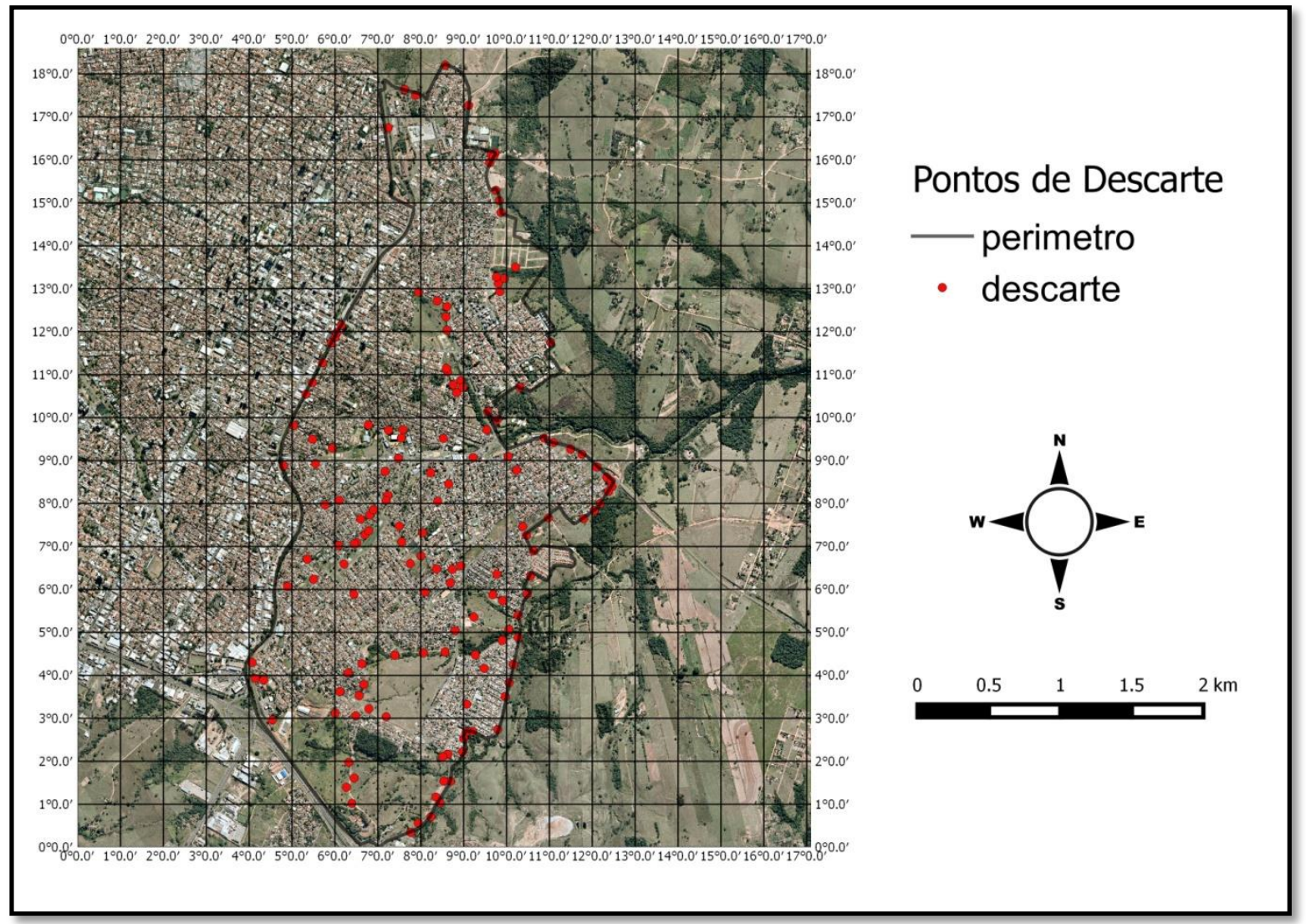

Figura 2. Mapa dos locais georreferenciado de descarte irregular ao longo da Zona Leste do Município de Presidente Prudente.

Fonte: Os Autores, 2016.

Ao longo destes pontos foram encontrados resíduos domiciliares: classificados como Classe II A - não inertes resíduos volumosos (móveis), resíduos recicláveis (plásticos papéis), resíduos eletrônicos (eletrodomésticos), podas de árvore, e resíduos da construção civil, como entulho, classificados segundo a resolução CONAMA n 307 como de Classe II B - inertes oriundos de reformas e construção.

Conforme pode ser observado na Figura 3, que exemplifica as situações mais frequentes ao longo dos 145 locais de disposição inadequada de resíduos. 

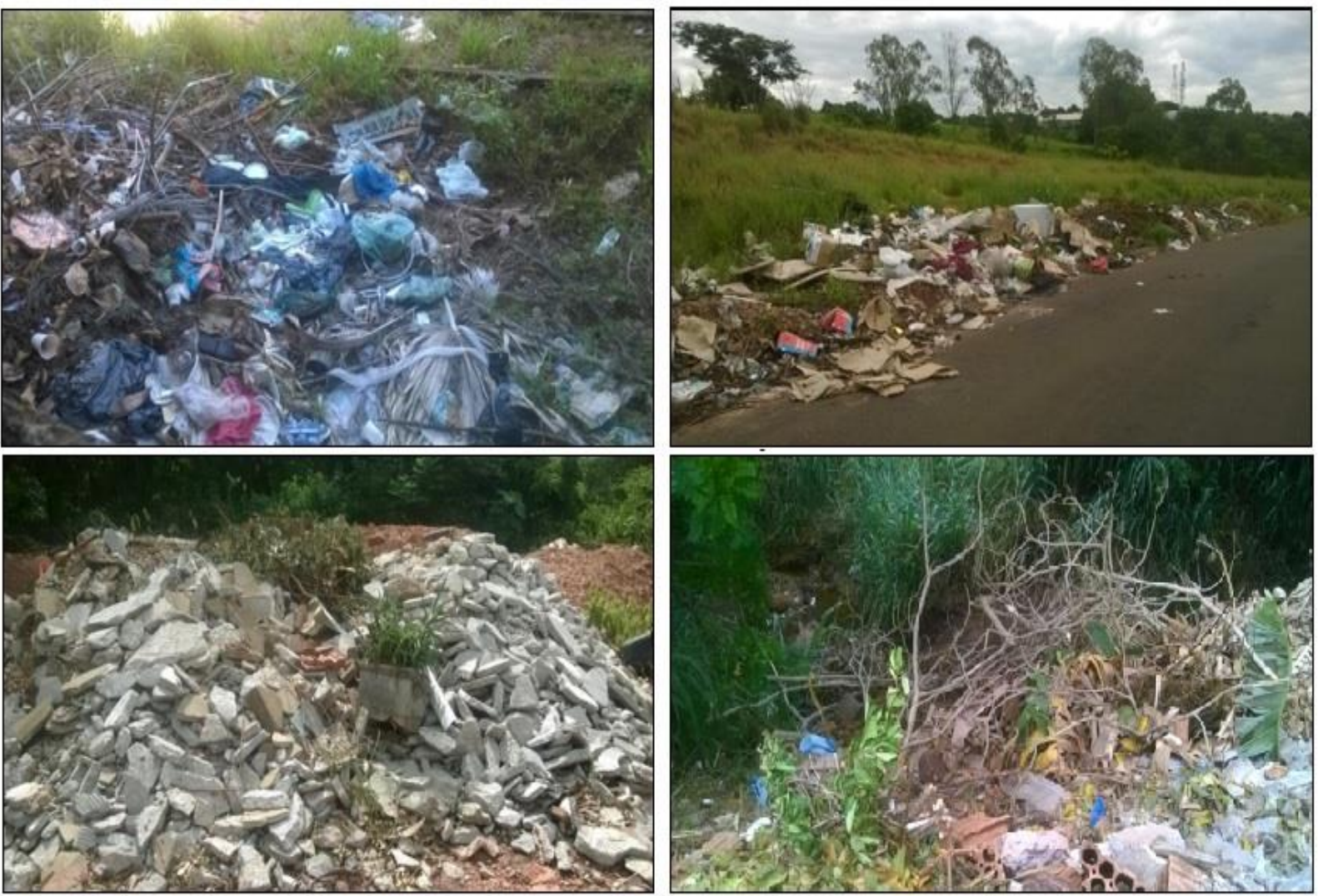

Figura 3. Pontos de Descarte Irregular de Resíduos Sólidos.

Fonte: Os Autores, 2016.

Por meio da análise da Figura 3 é possível notar que os pontos mais comuns de descarte são terrenos baldios, fundos de vale, áreas de proteção ambiental e margens de estradas.

A Figura 4 relata uma das situações mais frequente associada ao descarte irregular dos resíduos sólidos, que é a queima dos resíduos após o descarte.

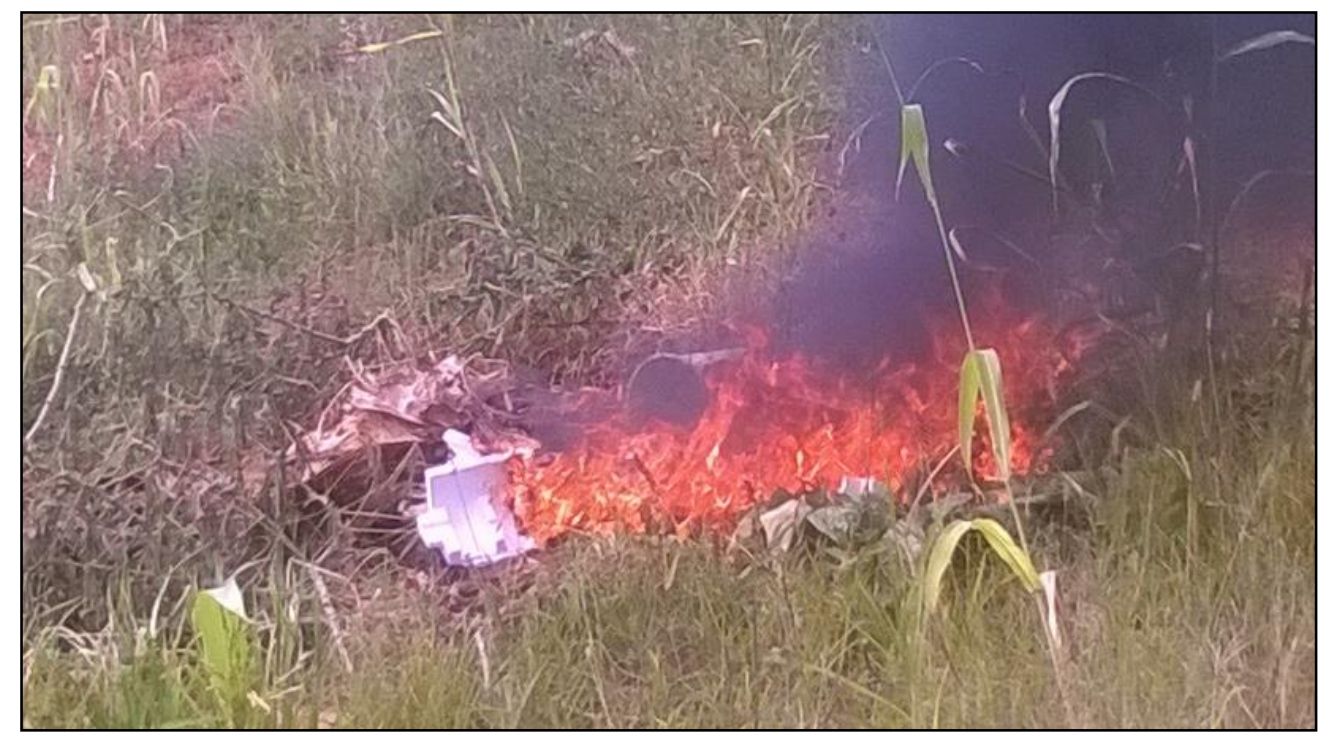

Figura 4. Queima dos resíduos descartados irregularmente na região periférica do município. Fonte: Os Autores, 2016.

Com base nas observações in loco elaborou-se uma Matriz de Interação Aspecto/ Impacto Ambiental relacionando os possíveis impactos ambientais ocasionados do descarte irregular desses resíduos, representados na Tabela 1. 
Sendo que, os impactos que demonstraram maior quantidade de interações foram: Alteração na qualidade das águas superficiais, a Poluição Visual e as Alterações nas Condições de Saúde.

A poluição visual é o primeiro impacto a ser notado e está presente em todas as áreas identificadas, e apesar deste ser um impacto que é facilmente solucionado através da limpeza dessas áreas também apresenta um grau maior de reincidência, devido à falta de educação ambiental apresentada pela população que reside próximo dessas áreas.

Tabela 1. Matriz de Interação Aspecto/Impacto Ambiental.

\begin{tabular}{|c|c|c|c|c|c|c|c|c|}
\hline & \multicolumn{8}{|c|}{ Impactos Ambientais } \\
\hline 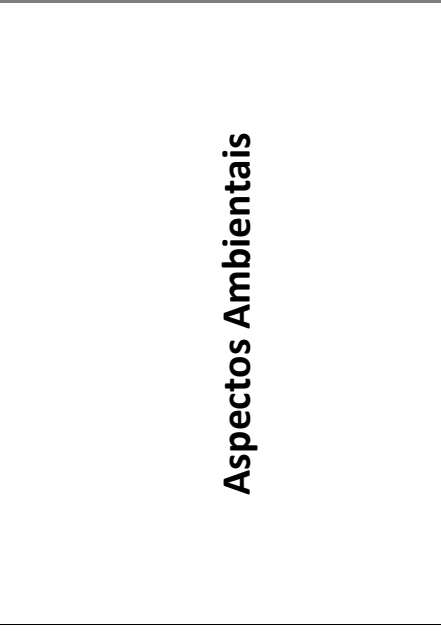 & 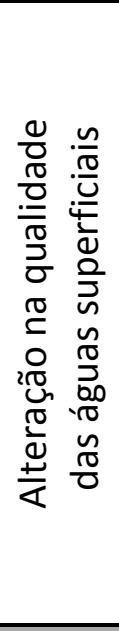 & 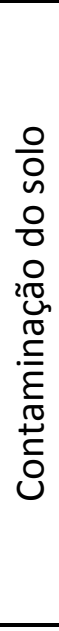 & 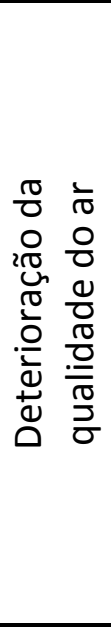 & 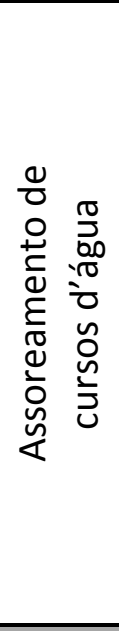 & 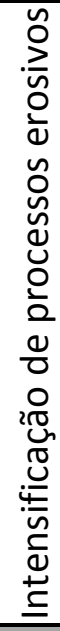 & 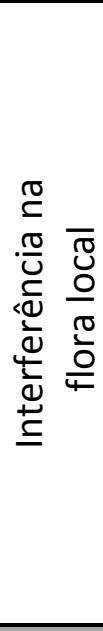 & 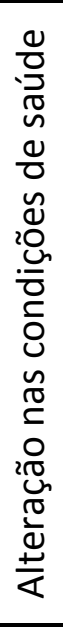 & $\begin{array}{l}\bar{\pi} \\
\frac{0}{3} \\
\frac{0}{2} \\
0 \\
200 \\
.00 \\
\frac{3}{0} \\
0\end{array}$ \\
\hline Modificação de Habitat & & & & & & & & \\
\hline $\begin{array}{c}\text { Alteração da Cobertura d } \\
\text { Solo } \\
\end{array}$ & & & & & & & & \\
\hline Proliferação de Vetores & & & & & & & & \\
\hline Acumulo de Resíduos & & & & & & & & \\
\hline $\begin{array}{l}\text { Geração de resíduos } \\
\text { perigosos (solventes, } \\
\text { tintas, metais pesados, } \\
\text { entre outros) }\end{array}$ & & & & & & & & \\
\hline Risco de Incêndio & & & & & & & & \\
\hline $\begin{array}{c}\text { Emissão de gases e de } \\
\text { material particulado }\end{array}$ & & & & & & & & \\
\hline
\end{tabular}

Fonte: Os Autores, 2016.

\section{DISCUSSÃO}

A disposição de resíduos de construção civil, resíduo doméstico e de restos de animais é bastante frequente na Zona Leste do Município. Observou-se que nos bairros estudados há predominância de descarte de resíduo domiciliar e da construção civil. Considerando a classificação da norma NBR 10004/2004 da ABNT, que trata da classificação dos resíduos, a maior parte do Resíduo da 
Construção Civil (RCC) é inerte, apresentando, portanto, baixa capacidade de contaminação química.

Porém vale salientar que os materiais como tintas, amianto, solventes e óleos, que são considerados resíduos perigosos (Classe I) também são encontrados nos RCC's, levantando assim a questão de que a classificação dos RCC's como inertes não deve ser considerada como uma verdade absoluta, sendo necessário um levantamento sobre a origem desse material para a devida classificação e destinação adequada, sem que cause danos ao meio ambiente (SILVA, 2014).

Outro fator que deve ser levado em conta ao se tratar deste tipo de resíduo é que o mesmo se caracteriza pelo grande volume, servindo como potencial abrigo para animais peçonhentos. Segundo Silva (2015), a frequente infestação de escorpiões pode estar relacionada às condições socioambientais decorrentes da ocupação humana, que interfere na dinâmica ecológica dos seres vivos, forçando-os a se adaptares as transformações ocorridas em seu habitat.

Esse amontoamento de resíduos também atrai inúmeros animais que podem disseminar doenças como a Leptospirose e a Toxoplasmose, transmitidas por ratos e urubus que buscam em meio aos resíduos seu alimento (SILVA; LIPORONE, 2011).

Além disso parte dos RCC's possuem a tendência de ser carreado pelas águas da chuva potencializando o assoreamento de córregos e rios principalmente se depositados em fundos de vale ou mesmo próximo deles (SILVA; LIPORONE, 2011). Fato que foi evidenciado em diversos pontos onde ocorria o descarte irregular de resíduos em áreas de preservação, nas quais foram registrados grandes volumes de resíduos depositados no curso d'agua.

A poluição visual decorrente desta prática de descarte transforma a paisagem em um cenário de degradação devido ao acúmulo de materiais ao longo das vias.

O acondicionamento e descarte inadequado dos RSU's também pode causar diversos problemas ambientais como a contaminação das águas subterrâneas e superficiais e do solo, devido ao lixiviamento de substâncias tóxicas presentes nos resíduos (MATOS et. al, 2011).

A queima dos resíduos agrava ainda os impactos ambientais decorrentes a disposição inadequada dos resíduos, pois a fumaça liberada faz mal à saúde devido à presença de poluentes como dióxido de carbono e material particulado. Além disso, é possível com que o fogo fuja do controle incendiando as construções ao redor ou a vegetação do entorno contribuindo ainda mais para a degradação ambiental.

Mudanças na legislação e o aumento da fiscalização acerca das ações ambientais promovidas pelos municípios tem auxiliado na busca e implantação de programas e projetos que visam a redução dos danos causados pelo descarte de resíduos. Entre as ações executadas pelos municípios vale ressaltar a implantação de programas de coleta seletiva dos resíduos recicláveis (AZEVEDO et al. 2004).

A implantação e o incentivo à esta atividade, que é uma das grandes responsáveis pela redução dos resíduos que seriam descartados em aterros ou lixões, proporciona também a possibilidade de geração de renda para a população, através da comercialização desses materiais.

Tavares et al. (2016) aponta que os maiores beneficiados da implantação do sistema de coleta seletiva são o meio ambiente e a saúde da população.

Vale salientar que a educação ambiental da população também é fator decisivo para o bom funcionamento da coleta seletiva. Por tanto, além dos investimentos aplicados nos sistemas de coleta e tratamento de resíduos recicláveis também é importante a elaboração e execução de ações educacionais voltadas à conscientização dos consumidores, abordando a comunidade como um todo, dentro e fora das salas de aula, através da inclusão e disseminação dos conceitos ambientais, desenvolvendo um pensamento crítico ambiental e de uma consciência ecológica nos indivíduos, tornando-os agentes transformadores da sociedade. 


\section{CONSIDERAÇÕES FINAIS}

O descarte inadequado de Resíduos Sólidos Urbanos é um dos principais problemas relacionados ao gerenciamento dos resíduos sólidos. Em Presidente Prudente, mesmo com a regularidade no sistema de coleta de resíduos urbanos, os bairros enfrentam os problemas de acúmulos de RSU's em áreas pontuais, que se estendem por mais de 145 pontos. A principal causa do descarte inadequado de resíduos sólidos é a falta consciência ambiental da população.

Dentre os impactos ambientais estão à poluição visual, do solo e do ar; proliferação de insetos e animais vetores de doenças.

Desta forma, o presente estudo consiste numa ferramenta de identificação de pontos de descarte irregular, que poderá auxiliar o planejamento e gerenciamento dos resíduos sólidos na formulação de uma política pública que vise solucionar esta problemática.

\section{REFERÊNCIAS}

ARAUJO, K.K.; PIMENTEL, A.K. A problemática do descarte irregular dos resíduos sólidos urbanos nos bairros vergel do Lago e Jatiúca em Maceió, Alagoas. Gestão \& Sustentabilidade Ambiental, v. 4 n. 2, p. 626-668, 2016. Disponível em: < http://www.portaldeperiodicos.unisul.br/index.php/gestao_ambiental/article/view/2762/2283>. Acesso em 27 de agosto de 2016.

AZEVEDO, G. O. D. POR MENOS LIXO: A minimização dos resíduos sólidos urbanos na cidade do Salvador/Bahia. 2004. Dissertação (Mestrado) - Escola Politécnica, Universidade Federal da Bahia, Salvador. Disponível em: < http://www.bvsde.paho.org/bvsacd/abes23/III-046.pdf>. Acesso em 27 de agosto de 2016.

MATOS, F. O. et. al. Impactos ambientais decorrentes do aterro sanitário da região metropolitana de Belém-PA: aplicação de ferramentas de melhoria ambiental. Caminhos de Geografia, v. 12, n. 39, p. 297 - 305, 2011. Disponível em: <http://www.ig.ufu.br/revista/caminhos.html>. Acesso em 01 de agosto de 2016.

SANTOS, H. M. C.; FELIPE, M. C. P. Influência da acessibilidade e externalidade no mercado imobiliário dos imóveis urbanos situados "além-linha" no município de Presidente Prudente. Colloquium Exactarum, v. 7, n. 4, p. 36-43, 2015. Disponível em: < http://revistas.unoeste.br/revistas/ojs/index.php/ce/article/view/1462/1490>. Acesso em 28 de agosto de 2016.

SILVA, C. B.; LIPORONE, F. Deposição irregular de resíduos sólidos domésticos em Uberlândia: Algumas considerações. Observatorium: OBSERVATORIUM: Revista Eletrônica de geografia, v.2, n.6, p. 22-35, 2011. Disponível em: http://www.observatorium.ig.ufu.br/pdfs/2edicao/n6/3.pdf>. Acesso em 28 de agosto de 2016.

SILVA, C. S. de S. da. Diagnóstico ambiental de áreas de disposição de resíduos da construção e demolição em Porto Alegre. 2014. Dissertação (Mestrado) - Universidade do Vale do Rio dos Sinos, São Leopoldo, RS. Disponível em: < ttp://www.repositorio.jesuita.org.br/handle/UNISINOS/4311>. Acesso em 28 de agosto de 2016.

SILVA, J.F. de A. da. Distribuição Geográfica dos Escorpiões no município de Presidente Prudente - SP nos anos de 2012 e 2013. 2015. Dissertação (Mestrado) - Universidade do Estadual Paulista UNESP. Presidente - Prudente SP. Disponível em: 
<http://repositorio.unesp.br/bitstream/handle/11449/124244/000830263.pdf?sequence=1\&isAll owed=y>. Acesso em 28 de agosto de 2016.

TAVARES, E. Sistemas de Tratamento e Disposição dos Resíduos Sólidos Compact Power \& Aterro Sanitário. 2008. Dissertação (Mestrado) - Universidade Jean Piaget. Cabo Verde. Disponível em: < http://bdigital.unipiaget.cv:8080/jspui/bitstream/10964/144/1/sistema\%20de\%20tratamento.pdf >. Acesso em 27 de agosto de 2016. 